\title{
USO DE REDE NEURAL ARTIFICIAL PARA DETERMINAR O ESTILO COGNITIVO DO APRENDIZ
}

\author{
Marina dos Santos Flores ${ }^{1}$, Rejane Frozza ${ }^{1,2}$, Daniela Bagatini ${ }^{1}$, Marcia E. J. \\ Kniphoff da Cruz ${ }^{1}$ \\ ${ }^{1}$ Departamento de Informática - Universidade de Santa Cruz do Sul (UNISC) \\ ${ }^{2}$ Programa de Pós-Graduação em Sistemas e Processos Industriais (UNISC) \\ Av. Independência, 2293 - 96815-900 - Santa Cruz do Sul - RS - Brazil \\ marynasf@gmail.com, \{frozza, bagatini,mcruz\}@unisc.br
}

\begin{abstract}
The learning has been the focus of intense study, especially on visible results that represent the mental processes by which the subjects are. However, it is necessary to intensify the study of how individuals learn, focusing on cognitive styles. In this sense, are presented partial results of research involving the technique of Artificial Neural Networks (ANN). Are developed a system that classifies RNAs cognitive style of the subjects. The theoretical bases which enable the classification of cognitive style are formed on Felder (1999) and Gardner (1994). The validation included 25 participants and showed positive results and also need to change at some points. The classification aims to create opportunities for learning different routes, as the cognitive style of the learner.
\end{abstract}

Resumo.A aprendizagem tem sido foco de intensos estudos, especialmente, sobre resultados visíveis que representam os processos mentais pelos quais passam os sujeitos. Contudo, é necessário intensificar o estudo sobre como os sujeitos aprendem, enfocando os estilos cognitivos. Neste sentido, são apresentados resultados parciais de pesquisa envolvendo a técnica de Redes Neurais Artificias (RNA). Foi desenvolvido um sistema de RNAs que classifica o estilo cognitivo dos sujeitos. As bases teóricas que permitem a classificação do estilo cognitivo são constituídas sobre Felder (1999) e Gardner (1994). A validação contou com 25 participantes e apontou resultados positivos $e$ também necessidade de alteração em alguns pontos. A classificação pretende oportunizar diferentes rotas de aprendizagem, conforme o estilo cognitivo do aprendiz.

\section{Introdução}

Com o uso dos ambientes virtuais de aprendizagem (AVAs), muitas questões relacionadas à qualidade do ensino virtual têm sido estudadas. Há uma crescente preocupação por parte dos pesquisadores em desenvolver sistemas cada vez mais inteligentes para o acompanhamento do estudante durante o processo de aprendizagem. Com isso, alguns ramos da Inteligência Artificial (IA) e das Ciências Cognitivas têm auxiliado no desenvolvimento de técnicas para identificar o estilo cognitivo do usuário que utiliza esses sistemas. Como forma de ampliar estes estudos, objetiva-se contribuir com esses avanços, apresentando como foco principal deste trabalho a descoberta e classificação do estilo cognitivo do usuário, neste caso chamado de aprendiz, com base na cognição. 
Este trabalho está pautado na classificação de estilos cognitivos de aprendizagem (ECA) de autores de referência, como Felder, Gardner, Kolb, Riding e Rayner, e nos estudos de Técnicas de IA, que são empregadas no auxílio à classificação desses estilos, mostrando que a área da IA tem muito a contribuir para a melhoria desses ambientes. Neste sentido, o objetivo principal deste trabalho é identificar o ECA de estudantes que interagem em um ambiente virtual de aprendizagem, utilizando a técnica de Redes Neurais Artificiais (RNAs) para a descoberta e classificação dos estilos cognitivos relacionados ao aprendizado. Como forma de coleta de dados, foram estruturados dois questionários para coletar as informações iniciais do estudante, e desenvolvido um sistema de Redes Neurais Artificiais que recebe como entrada as características do estudante e tem como saída o estilo cognitivo de aprendizagem ao qual pertence. O AVA identifica, a partir do ECA do estudante, qual a melhor estratégia de apresentação do material instrucional, apresentando conteúdos na forma como o aprendiz melhor se apropria deste conteúdo.

O artigo está organizado nas seguintes seções: a seção 2 aborda a relação entre a pesquisa e a cognição; a seção 3 apresenta os estilos cognitivos de aprendizagem estudados; a seção 4 destaca as características dos questionários e da rede neural desenvolvida; na seção 5 são apresentados os resultados atingidos; a seção 6 apresenta as conclusões do trabalho.

\section{O Contexto da Pesquisa e a Cognição}

Por este trabalho ter como peça chave os Estilos Cognitivos, se faz necessário estabelecer o significado de Cognição.

De acordo com Falvell (1999), este termo tem muitos significados e pode abranger vários conceitos ligados aos processos e produtos da mente humana, porém, não deixa de ser importante passar algumas ideias e imagens a respeito da natureza da cognição, mas não é nem possível e desejável defini-la e limitar seu sentido de maneira precisa ou inflexível.

Segundo o dicionário de psicologia de Dorsch (2001), a Cognição é um conceito comum para designar todos os processos ou estruturas que se relacionam com a consciência e o conhecimento, entre eles, a percepção e o pensamento. Com base neste conceito e de outros da psicologia, este trabalho utiliza como significado para o termo cognição as habilidades mentais necessárias para a obtenção do conhecimento. Habilidades estas que englobam o pensamento, raciocínio, abstração, linguagem, memória, atenção, criatividade, capacidade de resolução de problemas, entre outras funções.

A aplicabilidade destes conceitos é utilizada no desenvolvimento de diversos trabalhos na área das ciências cognitivas junto com a inteligência artificial, onde se objetiva prover uma melhor interação por parte de aprendizes em ambientes virtuais. Como exemplo, pode ser citado o trabalho de Barbosa (2003), que propõe uma metodologia para implementar um mecanismo de adaptação para interfaces adaptativas, em sites, utilizando a tecnologia de Redes Neurais. O mecanismo proposto é estruturado em três módulos: módulo do usuário, responsável por obter os dados do usuário e assim determinar suas Inteligências Múltiplas, baseado na Teoria das Inteligências Múltiplas de Gardner; módulo gerador de adaptação, que define a mídia como será apresentado o 
conteúdo utilizando RNAs para a tomada de decisão; e o módulo de interface, responsável pela interação do usuário com ambiente.

Outro trabalho que faz uso de perfis em um sistema web é o de Melo (2006), que propõe um Sistema Tutor Inteligente baseado também em RNAs capaz de oferecer ensino dinâmico e personalizado ao aprendiz. As características do perfil psicológico do aprendiz são utilizadas como elementos básicos da personalização, sendo complementadas por regras de especialistas, provendo o dinamismo necessário ao tutor.

\section{Estilos Cognitivos de Aprendizagem (ECA)}

O estilo cognitivo de um aprendiz descreve a sua forma individual, preferida e habitual, com que ele organiza e representa novas informações, enquanto ele executa uma tarefa de aprendizagem. Portanto, pressupõe-se que ao apresentar novas informações ao aprendiz, organizadas e representadas da forma como ele normalmente as organiza e as representa mentalmente, aumentaria a probabilidade de que este aprendiz, fácil e rapidamente, organizasse o seu pensamento e raciocinasse sobre as novas informações que lhe fossem apresentadas. Consequentemente, os benefícios psicopedagógicos estariam relacionados com: facilitar o desenvolvimento de uma tarefa de aprendizagem e aumentar a probabilidade de que o processo de aprendizagem seja mais eficiente e eficaz, melhorando o seu desempenho (SOUTO, 2003).

Foram estudados alguns autores de referência na área de Estilos Cognitivos, como Riding e Rayner, Kolb, Felder e Soloman, e Gardner. Cada um deles tem suas próprias classificações referentes aos estilos cognitivos de aprendizagem. Cada um dos estilos define maneiras típicas de um aprendiz perceber, recordar, pensar e resolver problemas. Essas classificações são resultados de longos estudos, baseados em classificações de outros autores e de suas próprias pesquisas com base em experiências práticas.

Apesar dos autores terem suas próprias classificações, observa-se que há vários pontos em comum entre os perfis. Também difere o contexto no qual aplicam ou exemplificam suas teorias, alguns voltados para ambientes de ensino, outros para uma aplicabilidade geral, seja no ambiente de trabalho, acadêmico, na resolução de problemas pessoais e cotidianos.

\subsection{Conjunto de ECAs Utilizados}

Após análise das diversas classificações dos autores citados, fez-se uma seleção dos estilos cognitivos de aprendizagem que podem ser utilizados e aplicados em um ambiente virtual de aprendizagem. Neste caso, utilizou-se um AVA desenvolvido por um grupo de pesquisa (FROZZA, 2011). Para a tomada de decisão, avaliou-se dois quesitos: O estilo pode ser aplicado em um ambiente de ensino e aprendizagem on-line? O estilo pode ser avaliado computacionalmente?

Quanto ao quesito "se pode ser aplicado em um ambiente de ensino e aprendizagem", levou-se em consideração se este estilo tem alguma validade quando confrontado com as características de um sistema virtual, onde a aprendizagem tem algumas restrições, e alguns estilos podem ser mais difíceis de serem identificados do que outros, como é o caso do estilo Intrapessoal de Gardner. O objetivo de tal estilo é a compreensão de si mesmo, de seus sentimentos e na resolução de problemas pessoais, o 
que é difícil de interpretar ou não tem valia para alguns sistemas de ensino e aprendizagem, já que o objetivo é aprender um conteúdo específico e não se preocupar com aspectos interiores do aprendiz.

Sobre o quesito de "poder ser avaliado computacionalmente", levou-se em conta a possibilidade de discernir um estilo de outro e classificá-lo através de técnicas computacionais e da Inteligência Artificial.

Para a composição deste trabalho, foi definida a utilização de uma combinação dos estilos de Gardner e Felder. Na tabela 1, são apresentadas as classificações dos ECAs selecionadas, divididas em duas partes: como o aprendiz trabalha o conteúdo (Felder) e como ele prefere que o conteúdo seja apresentado (Gardner), na forma de texto, figuras ou animação.

Tabela 1. Classificações selecionadas dos ECAs

\begin{tabular}{|c|c|l|}
\hline Autor & ECA & \multicolumn{1}{c|}{ Características do Aprendiz } \\
\hline Felder & Sensorial & $\begin{array}{l}\text { - Revisa os conteúdos e exercícios. } \\
\text { - Lê vários e diferentes exemplos. }\end{array}$ \\
\hline Felder & Intuitivo & $\begin{array}{l}\text { - Não revisa os conteúdos e exercícios. } \\
\text { - Prefere abstrações e fórmulas matemáticas. }\end{array}$ \\
\hline Felder & Ativo & $\begin{array}{l}\text { - Prefere trabalhar em grupos (fóruns, chats, envio de } e \text {-mails, } \\
\text { entre outros). } \\
\text { - Participa dos recursos interagindo e contribuindo com o grupo. }\end{array}$ \\
\hline Felder & Reflexivo & $\begin{array}{l}\text { - Prefere trabalhar sozinho. } \\
\text { - Quanto ao uso de fóruns, utiliza apenas para leitura. Não faz }\end{array}$ \\
\hline Felder & Sequencial & - Não faz saltos nos conteúdos. Segue o conteúdo passo a passo. \\
\hline Felder & Global & - Faz saltos nos conteúdos. \\
\hline Gardner & Linguístico-Verbal & - Prefere conteúdos no formato texto. \\
\hline Gardner & Visual-Espacial & - Prefere conteúdos em forma de imagens, desenhos, diagramas. \\
\hline Gardner & Cinestésico- Corporal & - Prefere conteúdos na forma de vídeo ou animação. \\
\hline
\end{tabular}

Definiu-se que haverá duas classificações por aprendiz, uma identificando como o aprendiz prefere que o conteúdo seja exibido (modelos de Gardner) e outra de como o aprendiz interage com o sistema (modelo de Felder).

\section{Funcionamento do Sistema de Redes Neurais Artificiais}

Nas seções a seguir, são apresentadas as etapas desenvolvidas para o funcionamento do sistema de Redes Neurais Artificiais (RNAs).

\subsection{Questionários}

O primeiro passo, para iniciar o desenvolvimento das RNAs, foi selecionar os formulários para proverem as informações de entrada para a rede neural artificial. Para 
isto, foram selecionados o "Questionário ILS (Index of Learning Styles)" de Felder e Soloman, responsável por identificar os estilos Ativo, Reflexivo, Sensorial, Intuitivo, Sequencial e Global; e o "Formulário Lista" de Armstrong (2007), que irá identificar os estilos Linguístico-Verbal, Visual-Espacial e Cinestésico-Corporal.

Além de selecionar os formulários, também foi necessário selecionar as perguntas ou afirmativas de cada um deles relativas aos estilos escolhidos para esse trabalho, pois os formulários originais abrangem mais estilos, de acordo com a classificação de cada autor.

Os formulários têm duas funções ao longo do desenvolvimento desse sistema. Primeiro, proporcionar os dados de entrada para a Rede Neural, onde os formulários serão submetidos a um grupo de usuários. Através dos dados obtidos com esses formulários, a RNA, já treinada, irá classificar o ECA de cada um desses usuários. Segundo, na fase de validação do sistema, esses formulários terão nova função, que é a comparação dos resultados obtidos da RNA com os resultados dos próprios formulários disponibilizados pelos autores. Serão comparados para verificar o grau de acerto da Rede Neural, e conforme necessário, seus ajustes.

\subsection{Técnica da IA Utilizada}

No desenvolvimento deste trabalho, preocupou-se em utilizar uma técnica da Inteligência Artificial que fosse possível de ser aplicada com precisão na classificação do ECA de aprendizes. Foi escolhida a técnica das Redes Neurais Artificiais pelo seu poder de processamento, com modelo similar de funcionamento do cérebro humano, e por já ser uma técnica muito conhecida e utilizada no reconhecimento de padrões e domínios relacionados à classificação de padrões.

Segundo Loesch (1996, apud FERNANDES, 2005), as Redes Neurais Artificiais são sistemas computacionais, de implementação em hardware e software, que imitam as "habilidades computacionais" do sistema nervoso biológico, utilizando, para isso, um grande número de neurônios artificiais interconectados.

A principal característica das Redes Neurais Artificiais reside na sua habilidade de adaptação e aprendizagem. Habilidade essa que pode lidar com dados imprecisos e situações que não estão completamente definidas. Uma rede depois de treinada tem a habilidade de generalização, quando é apresentada a entradas que não eram conhecidas anteriormente por ela (RESIGeT, 2011).

Para o treinamento da RNA foi selecionado o Algoritmo Backpropagation (figura 1), onde a rede irá operar em uma sequência de dois passos. Primeiro é apresentado um novo padrão à camada de entrada da rede, e através das conexões (pesos) se faz um cálculo sobre esses valores de entradas para passá-los à próxima camada, que fará o mesmo até a camada de saída. No segundo passo a saída obtida é comparada com a saída desejada para o padrão que está sendo treinado. Se a saída não é a desejada, o erro é calculado e retropropagado para as camadas anteriores, ajustando os pesos de cada conexão.

Este processo é repetido até que a saída obtida pela rede seja a saída desejada, para todos os padrões apresentados, com isso a rede estará estabilizada e pronta para uso. Então, é possível apresentar novos padrões à RNA, que não foram utilizados para 
treinamento, e a rede terá a habilidade de reconhecer estes com base no aprendizado anterior.

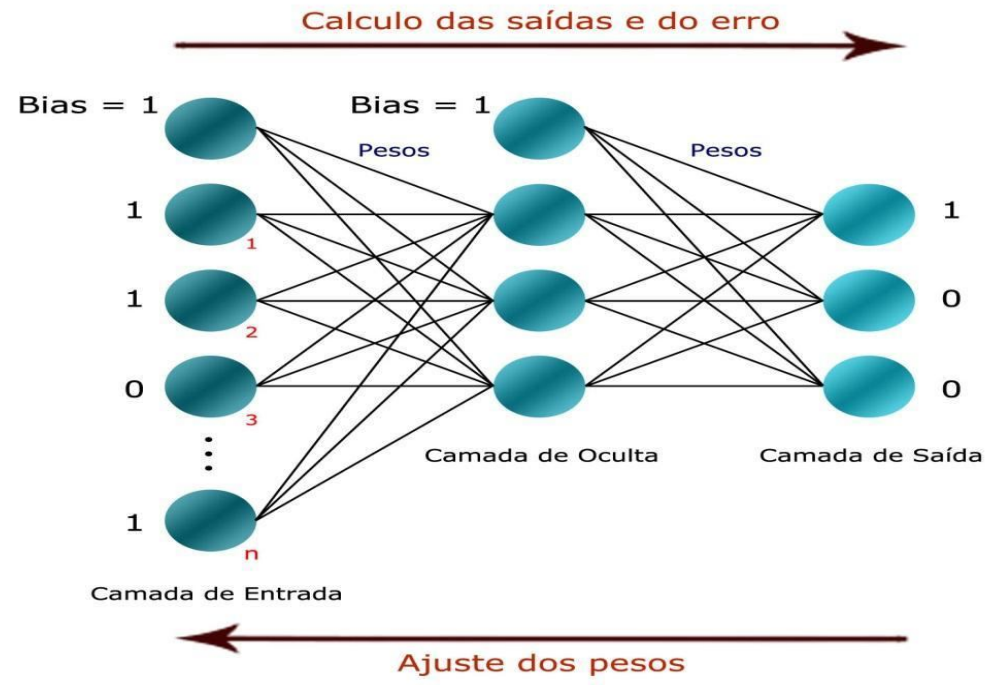

Figura 1. Funcionamento do Algoritmo Backpropagation

O sistema proposto faz uso de duas RNAs. Uma para a classificação do aprendiz nos modelos de Felder, e outra RNA para a classificação nos modelos de Gardner.

\subsection{Visão Geral do Funcionamento do Sistema}

A figura 2 mostra uma visão geral do funcionamento do sistema com as duas RNAs.

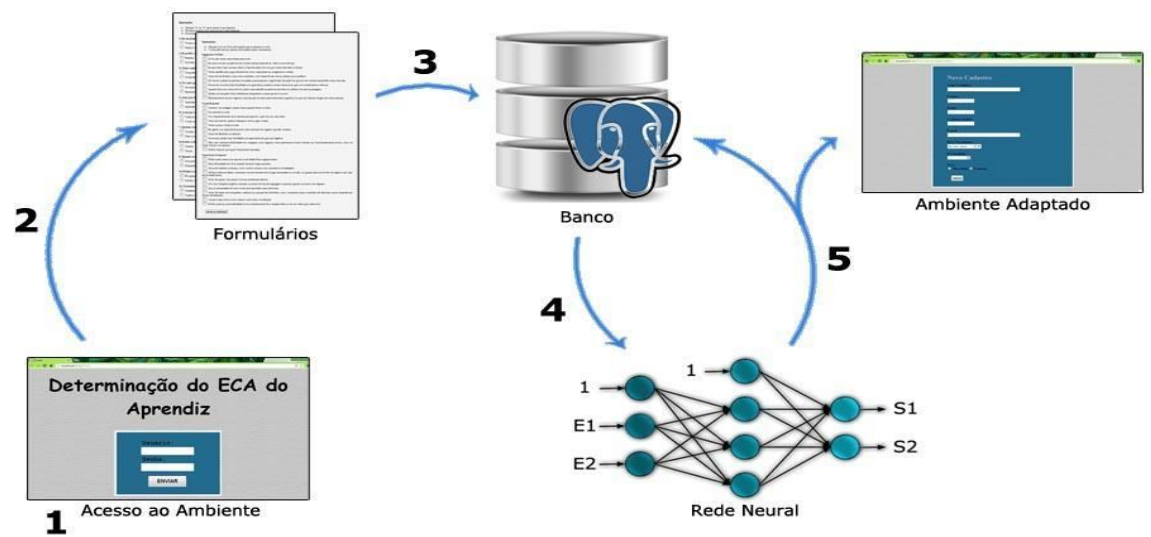

Figura 2. Funcionamento do Sistema

No passo 1, o aprendiz faz o acesso ao ambiente, onde deverá informar seu usuário e senha. Caso esse aprendiz ainda não tenha um usuário é possível criar através de uma opção (link) disposta logo abaixo da tela inicial. Depois de feito login pela primeira vez, o aprendiz é redirecionado para uma tela de Boas-vindas, onde são dadas instruções para os próximos passos que o aprendiz terá que seguir.

Após isso, é redirecionado para o passo 2, para preencher os dois formulários. Primeiramente será exibido o Formulário Lista de Gardner, responsável por capturar as 
características referentes ao modo como o conteúdo será exibido ao aprendiz. Se o conteúdo será exibido em forma de texto, diagramas, imagens, vídeos, entre outros. Depois de preenchido este primeiro formulário, será disponibilizado o Questionário ILS de Felder, responsável por capturar características do provável modo como o aprendiz irá interagir com o sistema, de acordo com os estilos selecionados de Felder.

Com os formulários preenchidos, as respostas do aprendiz são guardadas em Banco de Dados (passo 3), para sua posterior utilização. No passo 4 são enviadas as respostas de cada formulário gravadas em banco, uma por vez, para a camada de entrada da Rede Neural. Primeiro são enviadas as respostas do Formulário Lista e depois do Questionário ILS. Ao final do processamento da RNA e de seu resultado, no passo 5 é feita a gravação do ECA do aprendiz no banco de dados, vinculando ao usuário que acessou o ambiente. Também é retornado para o ambiente o ECA classificado, para realização das adaptações necessárias para a utilização pelo novo aprendiz. Com isso, termina o papel da rede neural, que passa o controle para o ambiente virtual de aprendizagem.

\subsection{Treinamento das RNAs}

Cada RNA foi treinada variando-se alguns parâmetros como: número de camadas da rede, número de neurônios intermediários, erro aceitável, número máximo de iterações e padrões apresentados à camada de entrada da rede. Cada treino da rede foi sucedido de um teste de desempenho, apresentando novas entradas desconhecidas pela rede, até se encontrar um arranjo de parâmetros que atingisse a melhor solução no reconhecimento dos estilos.

Para o treinamento da RNA de Gardner foram utilizados padrões com os valores “111111111100000000000000000000”, “000000000011111111110000000000” e “000000000000000000001111111111”. Cada padrão corresponde a um conjunto de valores 0 e 1 , onde cada valor equivale a uma resposta dada pelo aprendiz, no total de 30 questões. O número 1 significa a assertiva que o aprendiz marcou no formulário e 0 a que não marcou. Os padrões usados se referem respectivamente aos estilos LinguísticoVerbal, Visual-Espacial, Cinestésico-Corporal.

Já para o treinamento da RNA de Felder também foram utilizadas entradas com valores 0 e 1 , como também algumas respostas obtidas através do preenchimento do questionário de Felder, respondido por alguns estudantes e professores participantes dos testes. Como a maioria das pessoas que respondeu o questionário se enquadrou em dois ou três perfis apenas, foi necessário incrementar essas entradas com alguns dados fictícios, no intuito de abranger todos os estilos escolhidos e não apenas os obtidos através dos questionários.

Além desses parâmetros variáveis, também foram utilizadas de modo fixo no treinamento, a função de ativação Sigmoide, responsável pelo valor de saída de cada neurônio e a função do cálculo do erro das saídas da rede.

\section{Validação e Resultados}

Nas seções seguintes, será relatada a validação e os resultados obtidos pelas RNAs, com uma análise sobre estes resultados. 


\subsection{Validação}

O formulário e o questionário utilizados nesse trabalho foram retirados ou do estudo dos próprios autores que os formularam, como é o caso do questionário de Felder, ou de estudos de terceiros, como é o caso do formulário de Gardner que foi desenvolvido por Armstrong (2007). Com isso cada um desses autores desenvolveu uma forma de identificar o estilo cognitivo de aprendizagem através desses formulários ou questionários. Para certificar que a Rede Neural está trazendo resultados corretos, será comparada a saída da rede com o resultado calculado pelos questionários originais.

\subsection{Resultados}

$\mathrm{O}$ ambiente desenvolvido para testes foi utilizado por 25 estudantes que preencheram os questionários. Na figura 3 é mostrado o resultado obtido através da RNA de cada um dos autores e também o resultado real (desejado) segundo o formulário e questionário de cada autor.

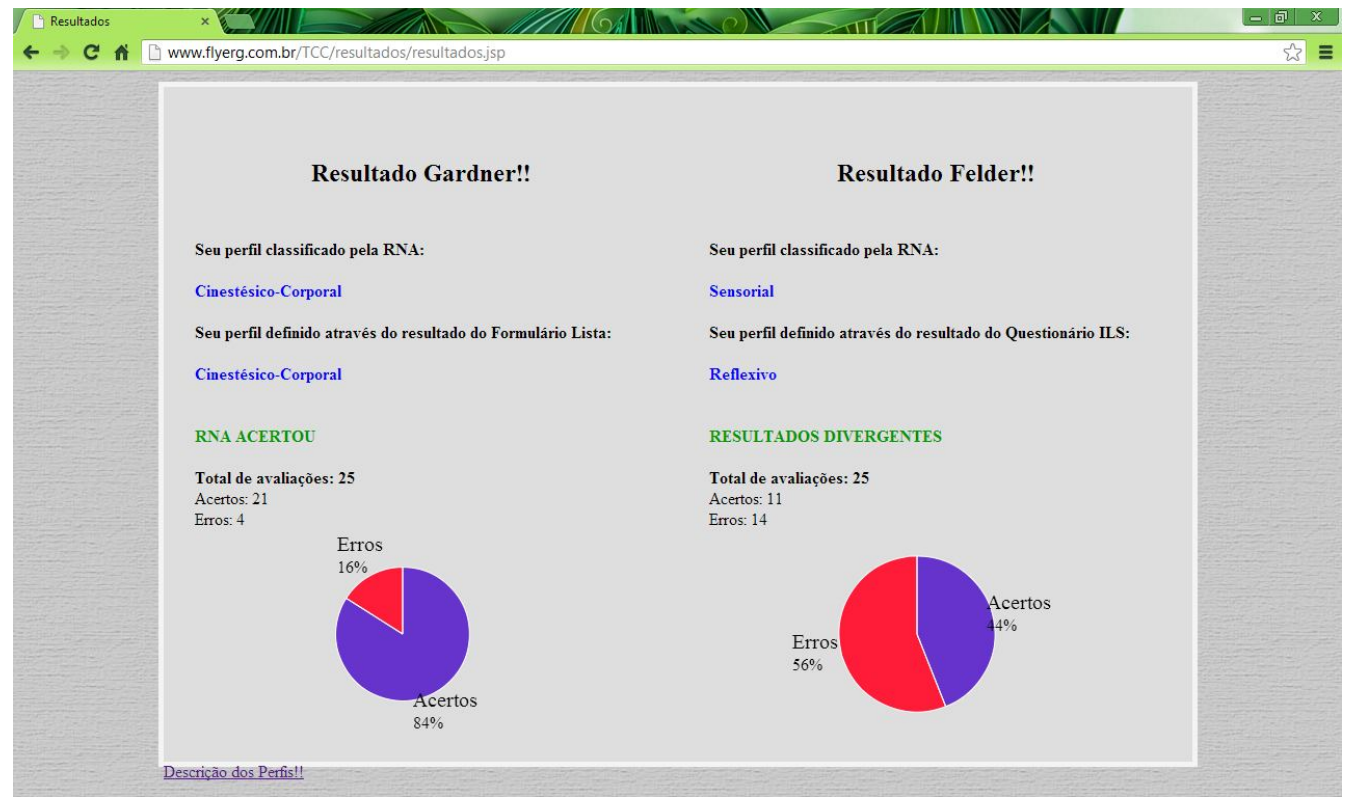

Figura 3. Resultados da RNA

Para avaliar o desempenho, foram disponibilizadas também as informações do total de avaliações feitas com a quantidade de erros e acertos de cada RNA, junto com um gráfico que ajuda a definir o percentual dos resultados. Avaliando o resultado final, observa-se que a RNA de Gardner teve bom desempenho, enquanto a RNA de Felder não obteve resultados tão satisfatórios quanto o esperado.

Com a análise dos resultados de cada RNA separadamente, com maior grau de detalhes, foi possível verificar o que levou a rede a retornar os resultados, em alguns casos, errados. Avaliando o resultado da RNA de Gardner de maneira geral, pode-se observar que teve um bom desempenho, como mostra o gráfico da figura 4. Com a análise minuciosa de alguns resultados que a RNA retornou, na busca da explicação para os quatro erros retornados, verificou-se que essas divergências se fizeram por conta da proximidade ou exatidão do número de respostas marcadas entre dois estilos diferentes do Formulário Lista de Gardner. Já observando o gráfico da figura 5 é 
verificado que o desempenho da RNA de Felder não satisfez as expectativas deste trabalho. O resultado das classificações foi negativo em comparação com o número de acertos.

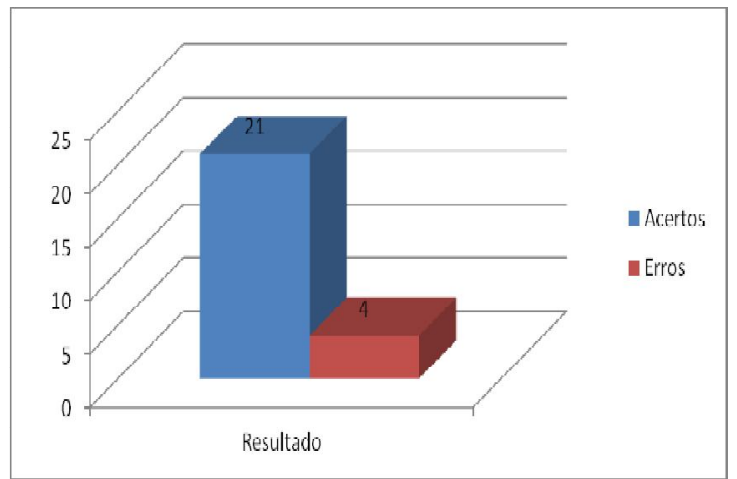

Figura 4. Resultado da RNA Gardner

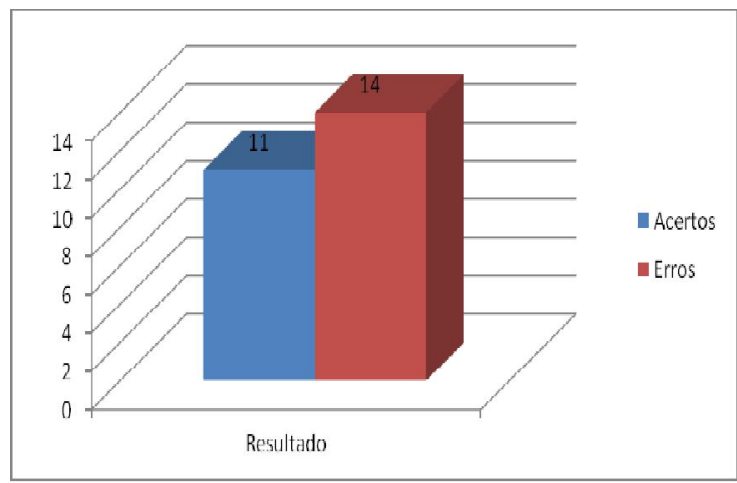

Figura 5. Resultado da RNA Felder

Verificando detalhadamente os resultados retornados, observa-se os motivos pelo retorno errado da rede, entre eles estão: a diferença acirrada entre respostas de dois ou mais estilos, onde a quantidade de respostas marcadas para um estilo é muito próxima da quantidade de outro estilo; um empate de respostas entre estilos, onde são marcadas as mesmas quantidades de respostas para dois ou mais estilos, podendo o aprendiz ser classificado em qualquer um dos estilos empatados. Isso se deve ao treinamento feito para esta rede, que não conseguiu obter a generalização. Mas isso pode ser resolvido com a realização de outros testes, a fim de ajustar os parâmetros da RNA para classificação dos estilos de Felder.

\section{Conclusão}

O campo de estudos dos estilos cognitivos em Ambientes Virtuais de Aprendizagem é amplo e representa uma imensa possibilidade para pesquisas. Muitos trabalhos têm mostrado avanços de melhoria desses ambientes, com resultados comprovados, conforme apresentado na seção 3. O desenvolvimento de técnicas para auxiliar os ambientes inteligentes começa a ser um requisito, com o objetivo de atingir todos os estilos cognitivos de aprendizagem e, assim, melhorar a qualidade de ensino e aprendizado, através de materiais personalizados.

Com os resultados deste trabalho, mostrou-se que as RNAs desenvolvidas têm importância para serem utilizadas em Ambientes Virtuais de Aprendizagem. Os resultados apresentados, apesar de nem sempre satisfatórios, comprovam a eficiência das redes neurais quando bem treinadas. A maior contribuição no desenvolvimento deste projeto, talvez nem seja o próprio desenvolvimento da RNA, com seus resultados comprovados. $\mathrm{O}$ valor maior está em todo o desenvolvimento do projeto, através dos estudos feitos, desenvolvimento do sistema e análise de cada resultado, pois estes sim demonstram todo o potencial deste "universo", que são as ciências cognitivas, servindo de inspiração para os próximos trabalhos a serem desenvolvidos.

Assim, este trabalho apresentou o desenvolvimento de um sistema utilizando Redes Neurais Artificias para identificar o estilo cognitivo do aprendiz, com base em um modelo de ECA proposto, atingindo seu principal objetivo. O conhecimento sobre 
os estilos cognitivos e a aplicação destes junto a uma técnica da IA se mostra muito importante no aprimoramento dos Ambientes Virtuais de Aprendizagem, uma vez que conhecendo o estilo do aprendiz se faz possível disponibilizar conteúdos na forma como ele melhor se apropria do conhecimento. Esta pesquisa continuará no sentido de envolver um número maior de participantes para ajuste dos modelos de RNAs desenvolvidos para identificação do ECA de aprendizes. O AVA sendo utilizado na pesquisa possui materiais desenvolvidos nos diferentes ECAs estudados e já está com as RNAs integradas ao ambiente.

\section{Referências}

ARMSTRONG, T. (2007). 7 Tipos de Inteligência. 3. ed. Rio de Janeiro: Record.

BARBOSA, A. T. R.; AZEVEDO, F. M. (2003) Metodologia para o desenvolvimento de um site com interface adaptativa usando redes neurais e a teoria das Inteligências Múltiplas. In: XIV Simpósio Brasileiro de Informática na Educação - SBIE, Rio de Janeiro.

DORSCH, F.; HACKER, H.; STAPF, K. H. (2001) Dicionário de Psicologia. Petrópolis: Editora Vozes.

FLAVELL, J. H.; MILLER, P. H.; MILLER, S. A. (1999) Desenvolvimento cognitivo. 3. ed Porto Alegre: Artmed.

FELDER, R.; SOLOMAN, B. A. (1999) Index of Learning Styles (ILS). Disponível em: <http://www4.ncsu.edu/unity/lockers/users/f/felder/public/ILSpage.html>. Acesso em: 28 ago. 2012.

FERNANDES, A. M. R. (2005) Inteligência Artificial: noções gerais. Florianópolis: VisualBooks.

FROZZA, R. et al. (2011) Agentes Pedagógicos Emocionais atuando em um Ambiente Virtual de Aprendizagem. Novas Tecnologias na Educação, v. 9, n. 1.

GARDNER, H. (1994) Estruturas da mente: A teoria das inteligências múltiplas. Porto Alegre: Artes Médicas Sul.

KOLB LEARNING STYLES. Disponível em: <http://www.businessballs.com/kolblearningstyles.htm>. Acessoem: 28 ago. 2012.

MELO, F. R.; MARTINS, W.; NALINI, L. E. G.; MEIRELES, V. (2006) Generalizador Neural de Espaços de Aprendizagem em Sistemas Tutores Inteligentes. In: XVII Simpósio Brasileiro de Informática na Educação - SBIE, Brasília.

RESIGeT - REVISTA ELETRÔNICA DE SISTEMAS DE INFORMAÇÃO E GESTÃO TECNOLÓGICA. Franca: v. 1, n. 1, 2011. Disponível em: <http://periodicos.unifacef.com.br/index.php/resiget>. Acesso em: 8 ago. 2013.

RIDING, R. e RAYNER, S. (2000) Cognitive styles and learning Strategies - understanding style differences in learning and behavior. London : David Fulton Publishers.

SOUTO, M. A. M. (2003) Diagnóstico on-line do Estilo Cognitivo de Aprendizagem do Aluno em um Ambiente Adaptativo de Ensino e Aprendizagem na Web: uma Abordagem Empírica baseada na sua Trajetória de Aprendizagem. Tese (Programa de Pós-Graduação em Computação), Universidade Federal do Rio Grande do Sul, Porto Alegre. 